\title{
Theory versus practise: Assessing reward-based crowdfunding theory through a South African case study
}

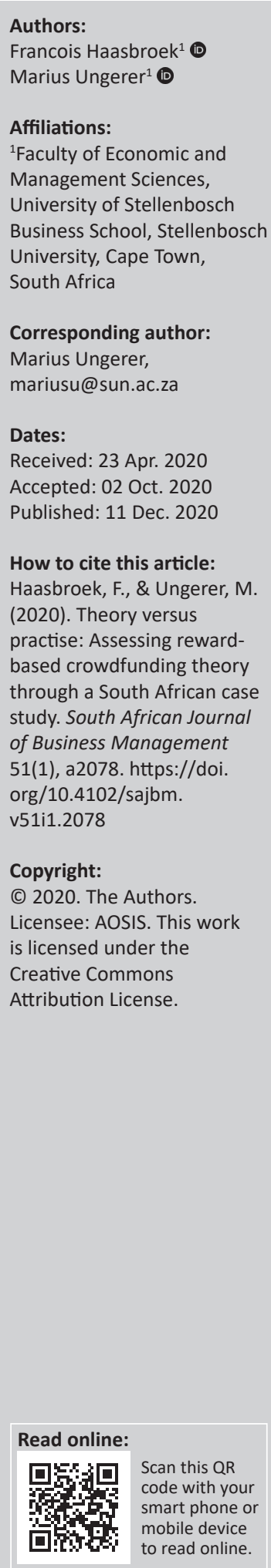

Purpose: This study was conducted to assess the replicability and efficacy of several key success factors (KSFs) as identified in reward-based crowdfunding (RBC) literature through a South African based case study. The dramatic rise and omnipresence of platform-driven enterprises and citizen participation have altered the social and business landscape over the past decade. Crowdfunding in its modern-day form is a fundamental embodiment of these two movements showing significant growth worldwide. Despite this growth, the theoretical development of crowdfunding emanates from a limited nexus of research, causing a lack of diversity in utilised data and applied methodologies. This study was conducted in response to these perceived shortcomings.

Design/methodology/approach: The research applied an inductive interpretivist research approach through data obtained from semi-structured interviews with 18 participants in a real-life RBC campaign in South Africa. Qualitative research techniques were utilised to analyse this data, including the researcher's field notes from the case.

Findings/results: This study's findings suggested that current literature on crowdfunding can benefit from additional contributions emerging from studies utilising alternative data sources and diversified methodologies. Moreover, several findings from this study expand on existing theories relating to participant incentives, campaign characteristics and management practices are associated with KSFs. This emerged because of the context-specific nature of this study utilising the participants' viewpoints in favour of historical quantitative data.

Practical implications: The findings provide reward-based crowdfunding practitioners deeper insight to key success factors which could influence campaign outcomes.

Originality/value: These findings contribute new theoretical knowledge about KSFs and its ability to incentivise participation in $\mathrm{RBC}$ and present practical recommendations to future RBC designers.

Keywords: campaign characteristics; key success factors; management practices; participant incentives; platform-driven enterprises; reward-based crowdfunding; South Africa.

\section{Introduction}

Crowdfunding across its several forms are a nascent and dynamically growing phenomenon worldwide. Despite this growth, there has been relatively little theoretical development in crowdfunding literature (Brown, Mawson, Rowe, \& Mason, 2018; Zhang, Baeck, Ziegler, Bone, \& Garvey, 2016). Furthermore, the existing body of work has predominantly relied on data from only a few large crowdfunding platforms, rarely investigating smaller market entities (Lagazio \& Querci, 2018; Yu, Johnson, Lai, Cricelli, \& Fleming, 2017). This lack of diversity and depth within the literature raises the question of how applicable and transferable the existing knowledge is to the numerous other platforms and markets (Stasik \& Wilczynska, 2018). The primary objective of this article was to assess the transferability and efficacy of key success factors (KSFs) as identified in existing literature to a reward-based crowdfunding (RBC) campaign based in an under-investigated market, South Africa.

Resource restrictions are commonly cited by entrepreneurs and researchers as a major hindrance in enterprise development and economic growth (Bellavitis, Filatotchev, Kamuriwo, \& Vanacker, 2017). The World Bank estimates crowdfunding could account for $\$ 300$ billion in cumulative transactions by 2025 (Meyskens \& Bird, 2015). This method of funding and obtaining assistance from 'the crowd' is viable to alleviate resource scarcity for those requiring assistance 
(Brown et al., 2018). It stands to reason that the viability of crowdfunding as a resource provider would be of particular relevance to interested stakeholders. Reward-based crowdfunding is one of several forms of crowdfunding, differentiated by the characteristic that funders could potentially receive a non-monetary return (Thürridl \& Kamleitner, 2016) compared with lending-base (monetary return), equity-based (share ownership) or donation-based (no return) formats. This study selected RBC as subject of investigation as it accounts for the largest number of active platforms across the world with minimal regulatory restrictions and low-risk of participation (Brown et al., 2018; Cox \& Nguyen, 2018; Massolution, 2013).

There seems to be a lack of understanding of RBC despite its economic growth and perceived potential (Mollick, 2014). From a management viewpoint, it is critical to understand the incentives and motivations of stakeholders in any crowdfunding ecosystem (platform operators, campaign founders and potential funders) for effective value creation (Clauss, Breitenecker, Kraus, Brem, \& Richter, 2018). This need for understanding has resulted in research primarily focusing on determining the KSFs of crowdfunding campaigns (Short, Ketchen, McKenny, Allison, \& Ireland, 2017) as KSFs should have theoretically incentivised funder participation. These proposed theoretical KSFs resulted from determining correlations between campaign attributes and campaign outcomes. As a result of the nascent nature of the industry, only selected platforms could supply rich enough data for meaningful quantitative research, accordingly $\mathrm{Yu}$ et al. (2017) found that the vast body of research have utilised only this small selection of platforms. Stasik and Wilczynska (2018) questioned the applicability and practical worth of these results to platforms outside those selected in these studies. In addition, no studies of RBCs were identified investigating particular case studies in detail.

The under-investigation of minor platforms and locations and the lack of insight gained from participants could be a knowledge void in our understanding of RBCs. This article will henceforth address the following two research questions: Firstly, are the KSFs identified in the current literature transferable and effective across RBC platforms? Secondly, are participants incentivised by the identified KSFs? After reviewing current RBC literature, the reported KSFs were identified, summarised and categorised. This study incorporated and actioned the identified KSFs into a real-life case study RBC campaign based in South Africa. The resulting findings provide new insight into and understanding of the participants' experiences, which could guide platform operators, campaign founders and potential funders on how to manage and optimally utilise a RBC campaign for maximal value creation in the future and contribute to the current theoretical knowledge.

\section{Theoretical overview of crowdfunding}

The overarching mechanism of crowdfunding is the facilitation, solicitation and distribution of relatively small financial contributions from a potentially large number of geographically diverse funders through an open call on an internet-based platform (Belleflamme, Lambert, \& Schwienbacher, 2014). The utilisation of internet-enabled mechanisms has created a new landscape and possibilities in accessing resources and disseminating information. The creation of this novel source of social and financial capital for entrepreneurial ventures and people in need of assistance has shown substantial growth and potential worldwide (Stevenson, Kuratko, \& Eutsler, 2019). Crowdfunding attracted relatively little scholarly attention initially (Mollick, 2014). As late as 2017, Short et al. (2017) found that understanding and scholarly knowledge remained lacking in relation to the perceived importance of the subject. Stasik and Wilczynska (2018) proposed that the rapid rate of development in the crowdfunding landscape complicated the gathering of accurate and complete data that is representable across regional, time-based and crowdfunding formats. The high-frequency use of Kickstarter, amongst others, as data source as reported by Yu et al. (2017) was because of the accessibility of large volumes of data, making these select platforms especially suitable for scientific study. Several scientists have indicated that their reliance on these select few large platforms as data sources were a research limitation in their studies (Chan, Park, Patel, \& Gomulya, 2018; Colombo, Franzoni, \& Rossi-Lamastra, 2015; Cox \& Nguyen, 2018; Wang, Li, Liang, Ye, \& Ge, 2018). Amongst these limitations are the question of transferability and relevance of findings to other platforms, categories or locations (Stasik \& Wilczynska, 2018).

The success rate of RBC campaigns is relatively low according to Mollick (2014), majority of campaigns fail by a large margin and success is only narrowly attained. As success of a campaign is solely determined by reaching a stated funding goal, the ability to attract and incentivise funders to contribute is critical. As such the majority of subsequent studies on crowdfunding have focused predominantly on determining campaign KSFs, as this knowledge could impact future campaign decisions and outcomes (Short et al., 2017). To this end these studies attributed campaign characteristics as potential KSFs through statistically correlating successful campaigns with individual campaign attributes. The study reported in this article identified these KSFs in a literature review and categorised and grouped them into 13 categories as indicated in Figure 1. The categories were chronologically arranged by relevance and importance during a RBC campaign - from pre-campaign and active campaign to postcampaign considerations.

The importance of each category varies relative to the study context and methodology and could not be quantified by importance. For this study, a selection of five KSF categories (No. 1: External social capital, No. 2: Geographical location, No. 6: Campaign content, No. 7: Rewards and No. 11: Communication) had particular relevance to the posed research questions. These KSF categories were selected to form the core focus of this article as the findings contribute to 


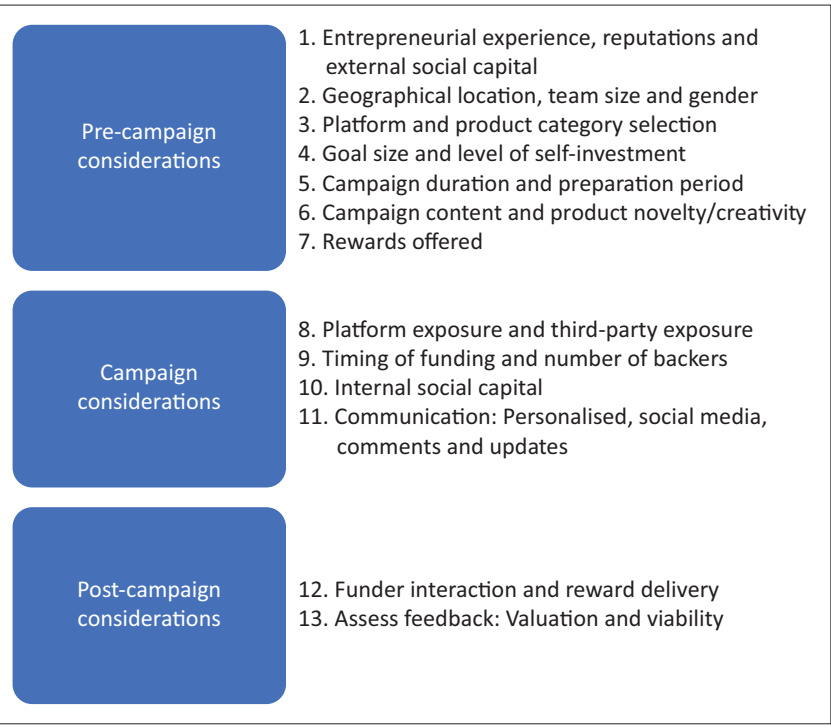

FIGURE 1: Crowdfunding key success factors (KSFs).

both managerial implications and novel theoretical knowledge. These five aspects are presented and discussed in more detail.

\section{Entrepreneurial experience, reputation and external social capital}

Several studies found the presence and effective utilisation of social capital as a key determinant of potential campaign success (Agrawal, Catalini, \& Goldfarb, 2011; Colombo et al., 2015; Giudici, Guerini, \& Rossi-Lamastra, 2018; Nahapiet \& Ghoshal, 1998; Skirnevskiy, Bendig, \& Brettel, 2017; Smith, Smith, \& Shaw, 2017). Of particular interest is external social capital, which is the direct network associated with founders, and which includes friends, family and colleagues. Skirnevskiy et al. (2017) further categorised this network as offline relationships, such as family and colleagues, and online relationships, such as social media acquaintances. This network is often an early-stage contributor to start-ups or crowdfunding campaigns because of the personal connection with founders which acts as an incentive for support (Colombo et al., 2015). Increased levels of trust and low information asymmetry are generally cited as reasons for this willingness towards early support (Agrawal et al., 2011). Early-stage support has been shown to be instrumental in the success of boot-strapping new ventures (Belleflamme et al., 2014).

This act of early support of a campaign could potentially incentivise undecided funders. An initial reluctance to support new or unknown enterprises exists because of the information asymmetry between founders and funders. Overcoming this reluctance and convincing potential funders is critical for project success. Several studies found that early-stage investing had significance because of the signalling effect to undecided funders (Colombo et al., 2015; Giudici et al., 2018; Skirnevskiy et al., 2017). The observable participation of others increases trust and reliance on the 'wisdom of the crowd', helping undecided participants to make a decision (Lambert, Ralcheva, \& Roosenboom, 2018). Early-stage participation by a critical number of funders is also associated with a herding effect. This creates a perception of high quality and legitimacy (Chan et al., 2018; Clauss et al., 2018) similarly found in bidding frenzies (Clauss et al., 2018) incentivising participation even though no new information regarding the campaign was provided.

The general consensus is that external social capital is important during a campaign's early stage, but reports on later-stage effects are less clear. Furthermore, not much has been reported on risks or managerial implications associated with utilising external social capital, in particular professional networks.

\section{Geographical location, team size and gender}

The locational effect of a founding team and platform has been the subject of several studies (Chan et al., 2018; Colombo et al., 2015; Courtney, Dutta, \& Li, 2017; Vismara, 2018). A key tenet of crowdfunding technology is the perceived ability to neutralise locational limitations (Anderson, 2006). Agrawal et al. (2011) found no proof that proximity between founders and funders resulted in a higher probability of campaign success. However, they did not eliminate other locational effects on the campaign such as local altruism, especially during early-stage support. Furthermore, the geographical clustering of certain industries, such as in Silicon Valley, could lead to support bias. Chan et al. (2018) thus suggested that the internet does not fully neutralise locational effects on all levels. No literature was found addressing the effect of location or the nationality of founders on accessing and utilising crowdfunding platforms, nor the probability of potential funders to be incentivised to partake in foreignbased campaigns.

\section{Campaign content and product novelty or creativity}

The internet lacks face-to-face interaction, and the presentation of campaign content serves as a proxy to mitigate this limitation by signalling legitimacy and trustworthiness to funders. The potential effects of campaign content have been reported on by multiple authors across platforms and locations with several reporting quantified values on content effects (Butticè, Colombo, \& Wright, 2017; Colombo et al., 2015; Courtney et al., 2017; Lagazio \& Querci, 2018). The most commonly found content elements reported on include:

1. Importance of campaign pitch content - videos, photos, text: investigation of funder reaction to key content elements, such as videos, photos and text (Bi, Liu, \& Usman, 2017; Davis, Hmieleski, Webb, \& Coombs, 2017; Lagazio \& Querci, 2018; Mollick, 2014) 
2. Decision criteria of less sophisticated investors based on signals and campaign content: the influence of content on decision making of non-professional investors ( $\mathrm{Li}$, Chen, Kotha, \& Fisher, 2017)

3. Effect of linguistic skills, grammar and spelling (Davis et al., 2017; Mollick \& Kuppuswamy, 2014; Parhankangas \& Renko, 2017)

4. Display of articles, patents, awards and organisational achievements and legitimisation (Ahlers, Cumming, Günther, \& Schweizer, 2015; Frydrych, Bock, Kinder, \& Koeck, 2014).

Campaign content is clearly widely reported to be correlated with RBC campaign success, by extension attracting and soliciting support or incentivising participation. The importance of the content to campaign success was determined by correlating presence or absence of each content component to successful campaigns.

\section{Rewards offered}

Reward-based crowdfunding is defined by the offer of a non-monetary reward to funders in return for monetary support. The presence of rewards should act as an extrinsic motivator to elicit support (Langley \& Leyshon, 2017). However, the effectiveness of rewards is questioned by Burtch, Ghose and Wattal (2013). Rewards usually align with the funding received, increasing in perceived value as the contribution rises. Thürridl and Kamleitner (2016) believed that reward determination by founders should be considered strategically. The considerations include all the resource requirements of creating or obtaining and delivering rewards as agreed on with the funders. Mollick (2014) found that over $75 \%$ of projects failed to deliver the agreed upon rewards on time. Marcum and Blair (2017) stated that this failure poses a significant risk of reputational harm or legal implications. Hence, rewards selection should aim to maximise visibility and convince funders and be within the founders' capabilities.

\section{Communication: Personalised, social media, comments and updates}

The final KSF reported on is the creation of a strategic and clear channel of communication to connect with, solicit and incentivise potential funders. Effective communication, networking and marketing of campaigns have been studied and reported on by authors such as Jank and Ku erová (2018), Parhankangas and Renko (2017), Paschen (2017) and Wang et al. (2018). Communication serves to inform and attract funders, create social ties and resolve queries. Lagazio and Querci (2018) highlighted the importance of effective marketing and the associated organisational abilities required to achieve this objective. Jank and Ku erová (2018) found an increased probability of campaign success in relation to campaign preparation period, including content preparation, pitches and communication relating to funders.
Social media is regarded as the de facto channel of communication facilitating an open discourse of commenting, highlighting and explaining aspects to interested parties (Clauss et al., 2018). This two-way transparent channel of communication via the internet has several benefits such as low cost and being nearly instant with extended reach (Agrawal, Catalini, \& Goldfarb, 2013; Bellavitis et al., 2017; Giudici et al., 2018). However, there are limitations to this format of communication. Langley and Leyshon (2017) contended that successful campaigns demand a near-constant effort of monitoring, instigating and interaction, requiring a non-negligible resource allocation. Marcum and Blair (2017) furthermore warned that negative comments or sentiments on social media can inflict significant reputational harm on founders, requiring constant monitoring and mitigation of concerns. The ability to reach a wide and diverse crowd is a defining characteristic of crowdfunding, enabling access to the long tail of the internet (Anderson, 2006) and dissolving inequities caused by distance separation. Selected platforms provide an additional channel of communication between founders and funders facilitated through comments and update capabilities.

The literature did not provide any clarity on an optimised strategy of marketing crowdfunding campaigns or incentivising participation.

\section{Research design and methodology Research paradigm and strategy}

An exploratory qualitative research approach was selected. Babbie (2010) highlighted the ability of this method to create new knowledge in underexplored topics. The study was grounded in interpretivism focused on creating understanding through the lens of social worlds within its context (Saunders, Lewis, \& Thornhill, 2009). Additionally, real-life case studies require the interdependent creation of multiple and subjective views (Harrison, Birks, Franklin, \& Mills, 2017), allowing immersion into the subjective views of the participants within their specific contextual reality (South Africa in this case).

\section{Study measures and criteria}

The case study campaign did not have to conform to any other prerequisites other than being based in South Africa and being reward-based in format. The category, product, firm, founders and goals were not considered in the selection as these variables were not under investigation.

The selected RBC case was a campaign for an entrepreneurial enterprise based in South Africa and focused on the creation of an ecologically friendly and sustainable shark barrier. The aim was to raise funds for additional research and development to expand the utility of the firm's core product. The crowdfunding platform Thundafund was selected with its keep-it-all funding model as it is the most recognised and 
largest RBC platform in South Africa. The researcher's involvement in this crowdfunding case required direct and continuous involvement in the design and execution of the campaign over several months to incorporate the identified KSFs into the campaign. The following KSFs, as identified in the literature review, were considered and incorporated into the creation of the case to the fullest extent possible to assess transferability and efficacy:

1. Reputation and utilisation of external social capital

2. Platform and product category selection

3. Goal size and level of self-investment

4. Campaign duration and preparation period

5. Campaign content and product novelty

6. Rewards offered

7. Third-party exposure

8. Communication.

Semi-structured interviews with campaign funders and founders were the source of primary data. The interview guide was composed to elicit subjective insights, experiences and opinions. Eight open-ended questions were posed to respondents and no ranking, scoring or objective judging was required. The key topics of interest elicited from the respondents were as follows:

1. (Dis-) Incentives for previous crowdfunding participation

2. Channels through which awareness of the case study were generated

3. Primary incentives for participation in the current crowdfunding case

4. Perception of campaign content and reward offerings

5. Incentives for potential future participation.

\section{Target population and sampling method}

A non-probability purposive (convenience) method was used to select the participants for the interviews (Kumar, 2005). The selection was stratified equally over the entire duration of the live campaign period of 30 days. Eligibility was restricted to individuals who financially contributed to the case campaign, regardless of the amount contributed. No other factors - such as gender, age, location, relation to founders and socio-economic factors affected eligibility. The potential population size could not be predetermined as there are no restrictions limiting participation in the campaign to a defined population.

The two campaign founders purposively selected as key informants were the chief executive officer and chief technical officer of the firm because of their direct involvement in the campaign.

\section{Data collection}

The research approach generated qualitative data from the case in the form of the researcher's learning log and interviews. The focus of this article is reporting on the analysis of the interviews contextualised with learning $\log$ notes. The crowdfunding platform enabled direct email communication between the founder and funder post-participation. A total of 35 potential respondents were contacted from a total of 46 eligible funders via email to request an interview, with 18 individuals agreeing resulting in a high sampling rate. The respondents received a written consent form stipulating the interview requirements and study objectives prior to the interview. All interviews were conducted by the researcher via Skype with voice recordings made on two separate recording devices. Otter.ai software was used for initial transcription of all interviews followed by a manual transcription to verify accuracy and to promote the dependability of the data. The quotations are reported using the identifiers I1 to I18 to honour the anonymity of the participants.

\section{Data analysis}

Atlas.ti qualitative analysis software was used for the first phase analysis, which entailed semantic analysis and the creation of frequency tables. The semantic findings were organised into seven individual groups based on topical relevance. Terre Blanche and Durrheim (2002) found that although the software is effective, it only serves as an aid. As such, the majority of the semantic coding was completed manually on MS Word. The second phase thematic coding was performed manually by integrating the semantic frequency table information with the contextual understanding of each respondent. An expert was consulted to gain opinions and critiques on the evolution of the theory and to promote credibility.

\section{Study findings and discussion}

The following section will firstly provide the findings of the semantic and thematic coding followed by relating these findings to the reviewed literature regarding the KSFs of RBC campaigns.

The findings of the first phase are illustrated in Figure 2 as a semantic and thematic relational framework emerging through a rigorous coding and indexing process (Babbie, 2010). Seven semantic groups emerged related to the funders' experience, opinions and interactions with the case. These semantic groups do not exist in isolation; they form an interrelated network nested within each respondent's history and experiences with RBC.

The second phase of the research process was the creation of four thematic groups emerging from the semantic groups, which are contextualised by quotations.

The thematic groups encompass several of the KSFs identified in the literature review. This article will report on the five significant KSFs as highlighted in the literature review and how it relates to each thematic group (Table 1). 


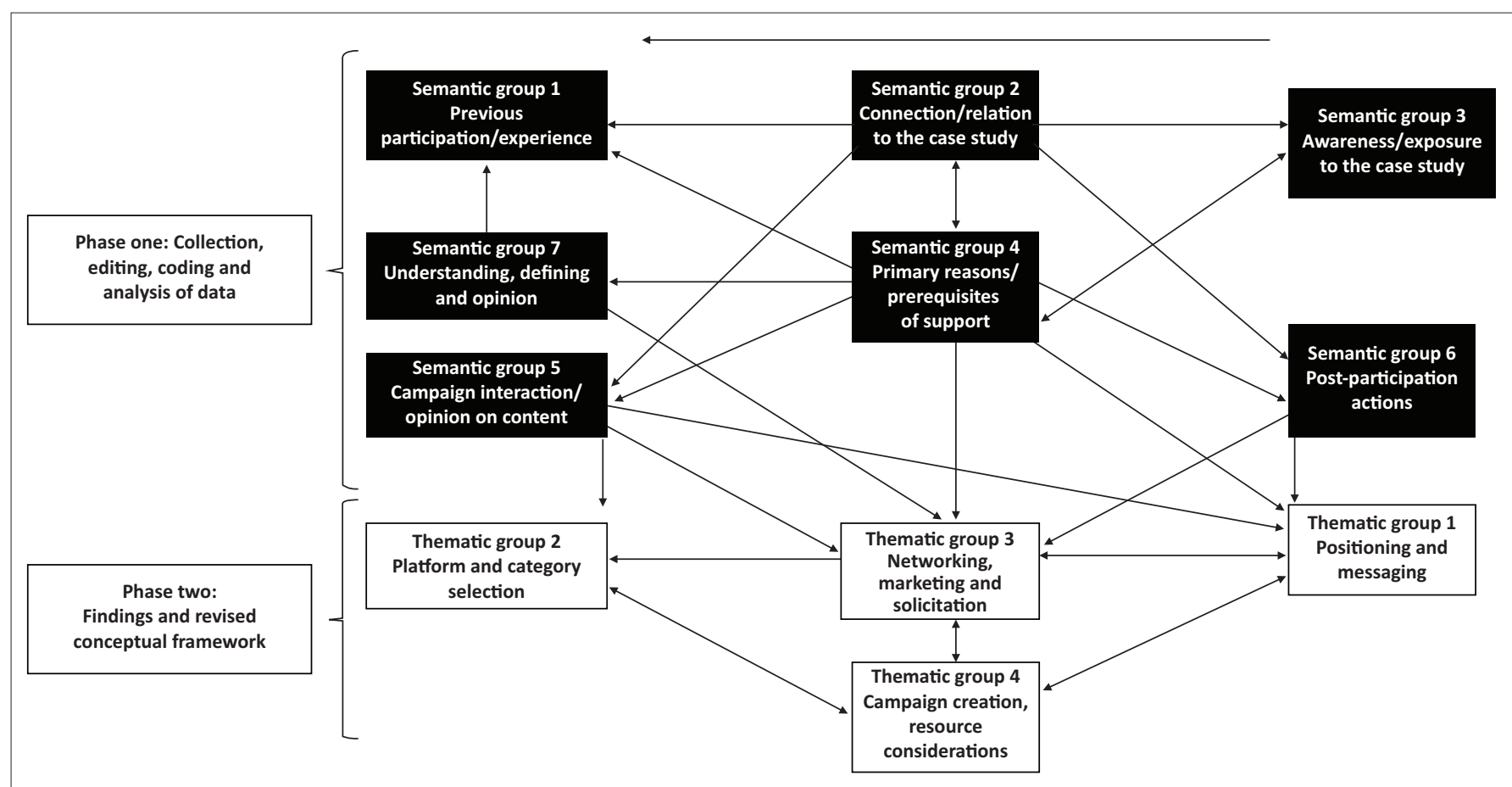

FIGURE 2: Semantic relational framework.

TABLE 1: Thematic relation to key success factors.

\begin{tabular}{ll}
\hline Thematic group & Relevant key success factors \\
\hline Positioning and messaging & 11. Communication \\
Platform and category selection & 2. Geographical location \\
Networking, marketing and solicitation & 1. External social capital \\
Campaign creation, resource considerations & 6. Campaign content \\
\hline & 7. Rewards offered \\
\hline
\end{tabular}

\section{The importance and value of external social capital}

The literature on the importance of external social capital as a KSF for RBC campaigns are extensive and conclusive (Agrawal et al., 2011; Colombo et al., 2015; Giudici et al., 2018; Skirnevskiy et al., 2017; Smith et al., 2017).

The relational map of the respondents' connection to the founders and the channels through which they obtained relevant campaign exposure is provided in Figure 3.

The findings revealed that the external social capital was overwhelmingly constructed from the interpersonal and inter-organisational networks of the founders, with only 4 of the 18 respondents having no direct relational link to the founders. This network was not just incentivised to contribute in monetary terms but also non-monetary contributions such as intellectual and human capital. This action speaks to bricolage theory and how founders actively supplement limited resources by utilising any available resources (Brown et al., 2018). This finding supports the existing literature that external social capital is an invaluable resource and KSF of successful RBC campaigns.

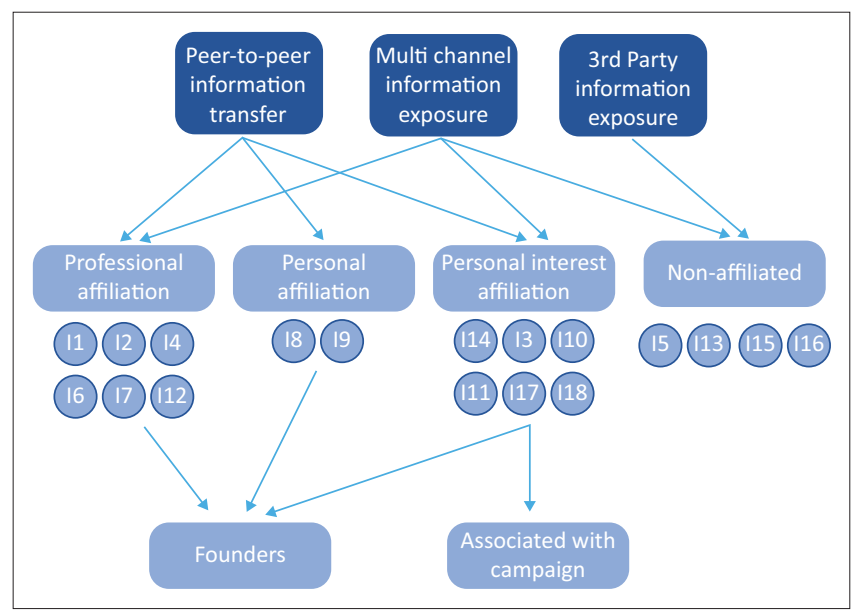

FIGURE 3: Relational map of founders and funders.

Although there is an agreement on the importance of external social capital in general, this study found the potential impact on and management of specifically the professional networks are underreported. Two key managerial considerations associated with utilising this specific external social capital network were identified. Firstly, selected respondents indicated reputational concerns because of risk-by-association as a concern preventing potential participation. Additionally, all professional contacts did not necessarily contribute after solicitation, potentially creating unforeseen future relational dynamics and concerns. The importance of effectively soliciting and obtaining support from the external social capital as a KSF is fully supported by this study. This study found that management of this network and specifically professional relations require careful consideration in terms of reputational risk, relational conflict and liability concerns. 


\section{Geographical location of founders and selected platform}

The ability of RBC platforms to reach and incentivise geographically dispersed prospective funders is mediated through the internet, theoretically neutralising locational limitations faced by founders (Anderson, 2006). This study found two indicators confirming this ability; firstly the number of foreign-based participants accounted for a significant number of funders and secondly their apparent lack of hesitance in utilising the selected South African RBC platform.

The geographical location of the founders did, however, pose a restriction, which we believe is a novel finding and not reported on in the reviewed literature. Although numerous crowdfunding platforms are present worldwide, Cox and Nguyen (2018) found an inequitable distribution of success amongst a limited number of platforms. Founders in this case reported a preference for utilising one such platform, Indiegogo, to theoretically increase exposure and probability of success. However, each platform has specific user rules and prerequisites. One such requirement was founders needed to be citizens or bank account holders within prescribed countries or jurisdictions. This requirement technically diminished the ability of non-eligible founders to attain equal visibility with eligible campaigns utilising these major European and US platforms. The founders of the campaign under research were not eligible to utilise their preferred crowdfunding platform and held the opinion that it negatively affected the campaign outcome. It was beyond

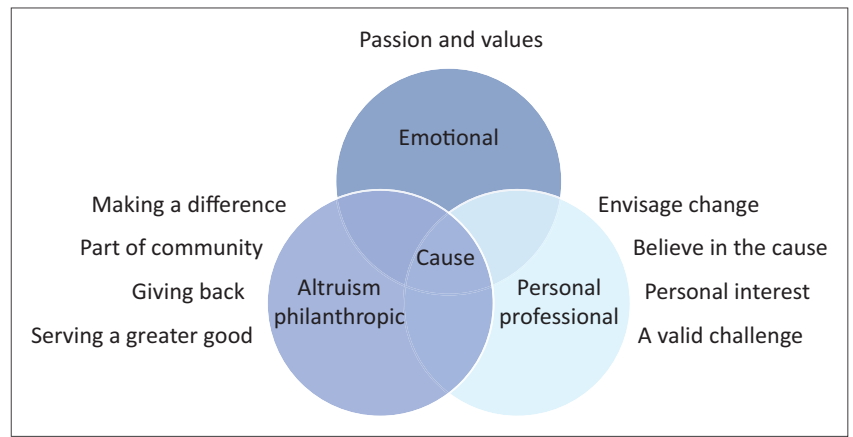

FIGURE 4: Relational framework of cause drivers. the scope of this study to conclude whether the campaign outcome would have been different if a major platform was used. This finding on geographical location contributed three insights. Firstly, the restrictive requirements of large platforms underscore Stasik and Wilczynska (2018) who questioned the value and transferability of results obtained from studies based on these selected large platforms. Secondly, founders need to be aware that access to any RBC platform is not guaranteed and the selection of alternative trustworthy platforms need consideration. Thirdly, the majority of participants were foreign nationals with no indication of concerns or hesitancy about using the South African platform, indicating minor RBC platforms are capable of incentivising support to RBC campaigns.

\section{The effect and influence of campaign content}

The perceived importance and effect of campaign content on incentivising funder support have been extensively studied and reported mostly through correlating campaign content elements with successful RBC campaigns. This study purposefully questioned the efficacy of campaign content as incentive for support by eliciting the subjective view of funders on their incentives for supporting the case.

The study found that all respondents were incentivised to participate as they wanted to support a cause (Figure 4).

All 18 respondents related to this campaign through these causal drivers: emotional, personal-professional and altruistic-philanthropic. Table 2 supplies supporting quotes from which nine individual themes emerged. The themes were categorised into the three overarching cause drivers.

This internal motivation appeared to be unaffected by any external incentives or factors, such as campaign content, as illustrated by the following:

'I didn't particularly go in and engage in detail with the material'. (I3, Female, South Africa)

'No, I didn't pay attention to if I saw the site now. I mean, I might not remember it'. (I12, Male, South Africa)

TABLE 2: Cause driver themes.

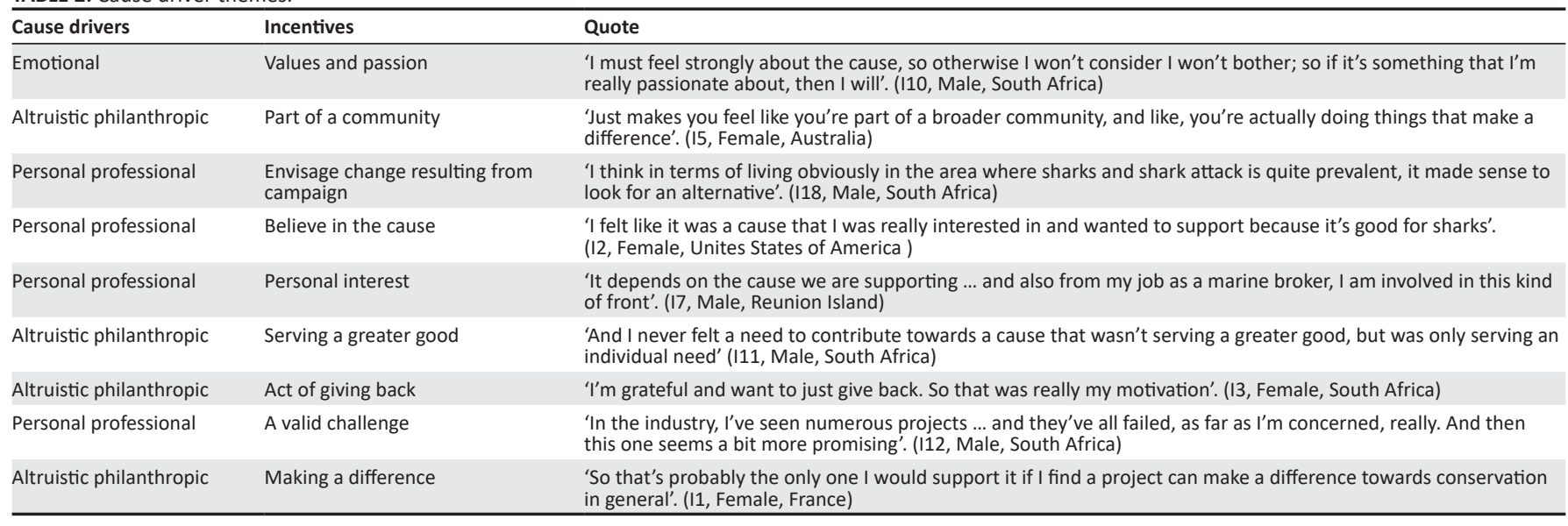


This study found no connection between campaign content and incentivising respondents' to participate in the campaign. The irrelevance of content was likely because of the respondents' cause incentive and participation was decided prior to observing the content. However, the study cannot discount that poor campaign content could result in a loss of support as content quality was noted by select respondents:

'... the descriptions were really attractive and very clear ...'. (I9, Female, Italy)

'... for me it was a great way to see, it was easy, it was convenient'. (I17, Male, South Africa)

Based on these findings, comprehending funder incentives appear critical to a founder's ability to identify and relate to the right crowd. The content provided should express a vision, mission and goals of the founders, which corresponds with those valued by the prospective funders, creating homophily, as mentioned by Smith et al. (2017), and incentivising subsequent support. The clear positioning and messaging strategy shared a common understanding and commonality in thought (Smith et al., 2017), which is similar to what was noted by respondents in this study. The finding questions the perceived importance and effect of campaign content to attract and incentivise participation as generally accepted. Although campaign content can potentially discourage support this study did not find any support that content incentivised support per se, at best the content served as an affirmation in the decision of support.

\section{Platform selection and the efficacy of rewards as incentive}

The literature suggests that rewards act as an extrinsic motivational trigger for potential funders and should be used strategically to incentivise support (Langley \& Leyshon, 2017; Thürridl \& Kamleitner, 2016). The desire of receiving a reward in lieu of financial support is often the singular incentive of funders (Gerber \& Hui, 2013). This study, however, concurs with Burtch et al. (2013) in questioning the impact of rewards on incentivising support. All respondents indicated they were either not incentivised by or unaware of rewards prior to participation:

'I didn't want any sort of rewards, T-shirts or anything like that, or rewards'. (I3, Female, South Africa)

'I didn't even know like you ... that were giving gifts away, like for the part of the donation like until I got there'. (I5, Female, Australia)

Of the 18 respondents, none indicated that the rewards acted as incentive or prerequisite for participation with only six opting in for a reward. The reaction and limited uptake of rewards are suggestive of what Janků and Kučerová (2018) called collective patronage. Our study further suggests that participants valued the act of helping more than receiving a reward (Chan \& Parhankangas, 2017). Rewards per se are thus not always a valid method to attract participants or elicit participation. This finding supports Burtch et al. (2013) who argued that at best the effectiveness of rewards is limited.
This negligible effect in incentivising participation poses a dilemma: Was a reward-based platform the optimal selection for this crowdfunding case? As the respondents selfidentified as supporting a social cause, Meyskens and Bird (2015) suggested such ventures with low economic worth (to funders) and high social worth should use donation-based crowdfunding instead. Yet, according to Paschen (2017), donation-based platforms have the highest failure rate across all crowdfunding formats, which is suboptimal. This study found that the use of a RBC platform did not incentivise participation per se but offered additional unexpected value to some funders. As such, it appears that RBC can be effectively utilised for the execution of social cause campaigns contrary to Meyskens and Bird (2015) conclusion and furthermore rewards offered potentially only serve a supporting role and not as a KSF.

\section{Communication, marketing and the solicitation of support}

To enable near-instant and borderless communication to attract and incentivise funders through internet is a fundamental feature of crowdfunding. A recurring finding was the perceived importance of an effective marketing strategy by founders and funders alike. However, neither expressed much understanding or comprehension regarding what was expected or required to achieve this objective. Current literature regarding specific marketing strategies for RBC campaigns, effects or methods are equally lacking in depth or detail. A proposed reason for this could be the general lack of research concerning antecedents of RBC campaigns compared with RBC outcomes.

This study did find it important to note that although networking and solicitation of support from external social capital are related to creating exposure through general marketing, it differs significantly in execution and resource requirements. Networking and solicitation require the utilisation of personal connections, person-to-person interactions and relationship management. Our study found that generalised marketing and exposure creation intended for incentivising general observers require more operational decisions such as content creation, advertising and resource allocation. The crowdfunding case reported on in this article found the need for managing this dual strategy, which satisfies both the general observer through marketing and soliciting support from personal networks. This finding elaborates on Langley and Leyshon (2017) and Marcum and Blair (2017) position that communication and solicitation require careful consideration and planning and the resource requirements are underestimated by founders.

\section{Conclusions and implications}

The ever-evolving and dynamic nature of technology are constantly testing existing norms. Platform technologies have proliferated across many aspects of our daily lives and presence and the utility is regarded as an integrated and often crucial component of modern society. Crowdfunding 
presents another form of platform technology, acting as an intermediary connecting those in need of assistance with those willing and able to assist. The act of soliciting resources from the general public is not a new or novel concept, but the advent of the internet-enabled technologies that shifted this paradigm.

The growth and reach of RBC is global, yet knowledge regarding the subject mostly originates from a select research nexus primarily being conducted on a small selection of platforms. The knowledge created from such studies undoubtedly carries value and has wider relevance on several levels. The question remains as to whether these findings are transferable and replicable in different contexts.

The current understanding of funder incentives has been restricted to theoretical assumptions based on testing quantitative correlations of campaign characteristics with outcomes. This article proposes the utilisation of underresearched platforms and integration of qualitative insights can narrow the gap between founders' needs and funders' wants, that is, better incentivise funder participation.

The findings of this study contribute both implications for practice and theoretical knowledge. Firstly, on a theoretical level this study has several findings that either elaborate on existing theory or contribute potentially new knowledge. Overall this study concluded that the attribution of campaign characteristic as KSFs for RBC campaigns does not fully account for or explain participant incentives. As the success of crowdfunding campaigns are solely determined by the participation of funders, it stands to reason that having a more comprehensive understanding of participant incentives would allow a more granular understanding of KSFs. This study stands in agreement with other studies that the utilisation of external social capital is a potentially critical resource for attaining campaign success. We furthermore contribute that the relational aspect of managing and incentivising in particular professional network connections are both an under-reported resource and require careful management. In regard to geographical location, the study found that an internet-mediated platform does enable the mitigation of locational restrictions. A novel insight related to the transferability of existing research results pertains to the limitation of founders not being allowed to utilise selected crowdfunding platforms. As the overwhelming majority of studies have been conducted on these aforementioned established platforms, the efficacy of their reported KSFs on alternative platforms to incentivise participants becomes less certain. A significant theoretical contribution of this study is calling into the question the perceived importance of campaign content and rewards offered to incentivise participation. We concluded the assumed importance as reported in the extant literature is not generalisable across RBC campaigns. The relevance of the rewards and campaign content are not discounted, we propose that RBC campaigns can be successfully conducted despite the content or rewards not necessarily because of it.
In terms of practical contributions, the intention of this article is to enable RBC stakeholders to optimise the incentivisation of potential participants. The first major contribution is highlighting the importance of external social capital as enablers of campaign success. This network of friends, family, colleagues and associates are not only more willing and able to assist with providing resources but their early participation can also greatly increase incentivising undecided participants. As reported in the theoretical contributions, founders have to be conscious of the potential relational and management concerns associated with this network of support. Secondly, the geographical location or nationality of campaign founders could determine which platforms are viable or permissible options, the legitimacy and potential reach of these platforms should be carefully considered. Furthermore, the creation of campaign content and the offering of rewards should not be viewed as a panacea for creating exposure or attracting funders, this study recommends that the creation of an effective marketing and networking strategy potentially has a more meaningful impact than content and rewards.

For any nascent technology to reach full utility, the reach and aspiration of research has to evolve with the technology. The objective of this study was to broaden the research scope and contribute to knowledge development regarding $\mathrm{RBC}$ in a South African context. The findings indicated several differences in the manner participants react to incentives, compared with expected behaviour according to existing literature. A key finding was the lack of incentive or motivation by rewards and campaign content when a cause was the driving motivator for participation. An additional finding was that social-impact campaigns can successfully utilise RBC to access resources. The study also concluded that the professional network of founders is currently understudied compared with the potential benefit it offers. This study did find the location or nationality of campaign founders can be restrictive in utilising select platforms. However, the locational effect did not prevent or dissuade geographically remote participants from actively supporting the campaign.

\section{Recommendations for further research}

Future studies can be conducted by actively participating, creating, executing and monitoring a marketing strategy for a crowdfunding campaign. This research would involve intimate involvement with the founders and project and require several months of participation. To obtain the full effect, the retention of participants as customers postcampaign should be monitored to determine the value of customer acquisition in relation to the resource cost of the campaign. Furthermore, the dynamics and potential relational management implications of soliciting and receiving crowdfunding support from professional networks could be worth investigating. A limitation of this study is being restricted to a single country and a single platform offers an additional avenue for conducting similar future research across multiple regions or platforms. 


\section{Acknowledgements Competing interests}

The authors have declared that no competing interests exist.

\section{Authors' contributions}

F.H. was the main author and M.U. the advisor and reviewer for the development of the manuscript. F.H. conducted the initial research as part of his MBA research assignment under the supervision of M.U.

\section{Ethical consideration}

The research received full ethical clearance from Stellenbosch University (No. 10542).

\section{Funding information}

This research received no specific grant from any funding agency in the public, commercial or not-for-profit sectors.

\section{Data availability}

Raw data were generated through personal in-depth interviews by F.H. Derived data supporting the findings of this study are available from the corresponding author (M.U.) on request.

\section{Disclaimer}

The views and opinions expressed in this article are those of the authors and do not necessarily reflect the official policy or position of any affiliated agency of the authors.

\section{References}

Agrawal, A.K., Catalini, C., \& Goldfarb, A. (2011). The geography of crowdfunding 16820. Cambridge. Retrieved from https://www.nber.org/papers/w16820.pdf

Agrawal, A.K., Catalini, C., \& Goldfarb, A. (2013). Some simple economics of crowdfunding. 19133. Cambridge: National Bureau of Economic Research. Retrieved from https://doi.org/10.3386/w19133

Ahlers, G.K.C., Cumming, D., Günther, C., \& Schweizer, D. (2015). Signaling in equity crowdfunding. Entrepreneurship: Theory and Practice, 39(4), 955-980. Retrieved n.d. from https://doi.org/10.1111/etap.12157

Anderson, C. (2006). The long tail (1st edn.). New York, NY: Hyperion. Retrieved from http://dl.motamem.org/long_tail_chris_anderson_motamem_org.pdf

Babbie, E. (2010). The pracrice of social research (12th edn.). C. Caldeira (Ed.) Belmont: Wadsworth Cengage.

Bellavitis, C., Filatotchev, I., Samuel Kamuriwo, D., \& Vanacker, Y. (2017) Entrepreneurial finance: New frontiers of research and practice. Venture Capital, 19(1-2), 1-16. https://doi.org/10.1080/13691066.2016.1259733

Belleflamme, P., Lambert, T., \& Schwienbacher, A. (2014). Crowdfunding: Tapping the right crowd. Journal of Business Venturing, 29(5), 585-609. https://doi org/10.1016/j.jbusvent.2013.07.003

Bi, S., Liu, Z., \& Usman, K. (2017). The influence of online information on investing decisions of reward-based crowdfunding. Journal of Business Research, 71, 10-18. https://doi.org/10.1016/j.jbusres.2016.10.001

Brown, R., Mawson, S., Rowe, A., \& Mason, C. (2018). Working the crowd Improvisational entrepreneurship and equity crowdfunding in nascent entrepreneurial ventures. International Small Business Journal: Researching Entrepreneurship, 36(2), 169-193. https://doi.org/10.1177/0266242617729743

Burtch, G., Ghose, A., \& Wattal, S. (2013). Secret admirers: An empirical examination of information hiding and contribution dynamics in online crowdfunding. Information System Research, 27(3), 478-496. https://doi.org/10.1287/ isre.2016.0642

Butticè, V., Colombo, M.G., \& Wright, M. (2017). Serial crowdfunding, social capital, and project success. Entrepreneurship: Theory and Practice, 41(2), 183-207. https://doi.org/10.1111/etap.12271
Chan, C.S.R., \& Parhankangas, A. (2017). Crowdfunding innovative ideas: How incremental and radical innovativeness influence funding outcomes. Entrepreneurship: Theory and Practice, 41(2), 237-263. https://doi.org/10.1111/etap.12268

Chan, C.S.R., Park, H.D., Patel, P., \& Gomulya, D. (2018). Reward-based crowdfunding success: Decomposition of the project, product category, entrepreneur, and location effects. Venture Capital, 20(3), 285-307. https://doi.org/10.1080/1369 1066.2018.1480267

Clauss, T., Breitenecker, R.J., Kraus, S., Brem, A., \& Richter, C. (2018). Directing the wisdom of the crowd: The importance of social interaction among founders and the crowd during crowdfunding campaigns. Economics of Innovation and New Technology, 27(8), 731-51. https://doi.org/10.1080/10438599.2018.1396660

Colombo, M.G., Franzoni, C., \& Rossi-Lamastra, C. (2015). Internal social capital and the attraction of early contributions in crowdfunding. Entrepreneurship: Theory and Practice, 39(1), 75-100. https://doi.org/10.1111/etap.12118

Courtney, C., Dutta, S., \& Li, Y. (2017). Resolving information asymmetry: Signaling, endorsement, and crowdfunding success. Entrepreneurship: Theory and Practice, 41(2), 265-290. https://doi.org/10.1111/etap.12267

Cox, J., \& Nguyen, T. (2018). Does the crowd mean business? An analysis of rewardsbased crowdfunding as a source of finance for start-ups and small businesses. Journal of Small Business and Enterprise Development, 25(1), 147-162. https:// doi.org/10.1108/JSBED-05-2017-0165

Davis, B.C., Hmieleski, K.M., Webb, J.W., \& Coombs, J.E. (2017). Funders' positive affective reactions to entrepreneurs' crowdfunding pitches: The influence of perceived product creativity and entrepreneurial passion. Journal of Business Venturing, 32(1), 90-106. https://doi.org/10.1016/j.jbusvent.2016.10.006

Frydrych, D., Bock, A.J., Kinder, T., \& Koeck, B. (2014). Exploring entrepreneuria legitimacy in reward-based crowdfunding. Venture Capital, 16(3), 247-269. https://doi.org/10.1080/13691066.2014.916512

Gerber, E., \& Hui, J. (2013). Crowdfunding: Motivations and deterrents for participation. ACM Transactions on Computing-Human Interaction, 20(6), 34, 1-32. https://doi.org/10.1145/2530540

Giudici, G., Guerini, M., \& Rossi-Lamastra, C. (2018). Reward-based crowdfunding of entrepreneurial projects: The effect of local altruism and localized social capital on proponents' success. Small Business Economics, 50(2), 307-324. https://doi. org/10.1007/s11187-016-9830-x

Harrison, H., Birks, M., Franklin, R., \& Mills, J. (2017). Case study research: Foundations and methodological orientations. Forum Qualitative Sozialforschung / Forum: Qualitative Social Research, 18(1), 1-12. https://doi.org/10.17169/FQS-18.1.2655

Janků, J., \& Kučerová, Z. (2018). Successful crowdfunding campaigns: The role of project specifics, competition and founders' experience. Finance a Uver-Czech Journal of Economics and Finance, 68(4), 351-373.

Kumar, R. (2005). Research methodology (1st edn.). London: Sage.

Lagazio, C., \& Querci, F. (2018). Exploring the multi-sided nature of crowdfunding campaign success. Journal of Business Research, 90(May), 318-324. https://doi. org/10.1016/j.jbusres.2018.05.031

Lambert, T., Ralcheva, A., \& Roosenboom, P, Cumming D., Hornuf L. (eds) (2018). The crowd-entrepreneur relationship in start-up financing. In D. Cumming \& L. Hornuf (Eds.), The economics of crowdfunding: Startups, portals and investor behavior (1st edn., pp. 57-78). London: Palgrave Macmillan. https://doi.org/10.1007/9783-319-66119-3_4

Langley, P., \& Leyshon, A. (2017). Capitalizing on the crowd: The monetary and financial ecologies of crowdfunding. Environment and Planning A, 49(5), 1019-1039. https://doi.org/10.1177/0308518X16687556

Li, J.J., Chen, X.P., Kotha, S., \& Greg, F. (2017). Catching fire and spreading it: A glimpse into displayed entrepreneurial passion in crowdfunding campaigns. Journal of Applied Psychology, 102(7), 1075-1090. https://doi.org/10.1037/apl0000217

Marcum, T.M., \& Blair, E.S. (2017). Over- and under-funding: Crowdfunding concerns of the parties involved. DePaul Business \& Commercial Law Journal, 16(1), 1-25. Retrieved from http://search.ebscohost.com/login.aspx?direct=true\&db=bth\&A $\mathrm{N}=130335702 \&$ site=ehost-live

Massolution. (2013). The crowdfunding industry report - 2013CF. Massolution 1-97. Retrieved from http://www.crowdsourcing.org/editorial/2013cf-thecrowdfunding-industry-report/25107

Meyskens, M., \& Bird, L. (2015). Crowdfunding and value creation. Entrepreneurship Research Journal, 5(2), 155-166. https://doi.org/10.1515/erj-2015-0007

Mollick, E. (2014). The dynamics of crowdfunding: An exploratory study. Journal of Business Venturing, 29(1), 1-16. https://doi.org/10.1016/j.jbusvent.2013.06.005

Mollick, E., \& Kuppuswamy, V. (2014). After the campaign: Outcomes of crowdfunding pp. 1-18. UNC Kenan-Flagler Research Paper No. 2376997. https://doi. org/10.2139/ssrn.2376997

Nahapiet, J., \& Ghoshal, S. (1998). Social capital, intellectual capital, and the organizational advantage. Academy of Management Review, 23(2), 242-266.

Parhankangas, A., \& Renko, M. (2017). Linguistic style and crowdfunding success among social and commercial entrepreneurs. Journal of Business Venturing, 32(2), 215-236. https://doi.org/10.1016/j.jbusvent.2016.11.001

Paschen, J. (2017). Choose wisely: Crowdfunding through the stages of the startup life cycle. Business Horizons, 60(2), 179-188. https://doi.org/10.1016/j. bushor.2016.11.003

Saunders, M., Lewis, P., \& Thornhill, A. (2009). Understanding research philosophy and approaches to theory development. In Research methods for business students (5th edn. p. 614). London: Pearson. Retrieved from https://www.researchgate.net/ publication/330760964_Research_Methods_for_Business_Students_Chapter_4 publication/330760964_Research_Methods_for_Business_Students_Chapter_4
Understanding_research_philosophy_and_approaches_to_theory_development 
Short, J.C., Ketchen, D.J., McKenny, A.F., Allison, T.H., \& Ireland, R.D. (2017). Research on crowdfunding: Reviewing the (very recent) past and celebrating the present. on crowdfunding: Reviewing the (very recent) past and celebrating the present. etap.12270

Skirnevskiy, V., Bendig, D., \& Brettel, M. (2017). The influence of internal social capital on serial creators' success in crowdfunding. Entrepreneurship: Theory and Practice, 41(2), 209-236. https://doi.org/10.1111/etap.12272

Smith, C., Smith, J.B., \& Shaw, E. (2017). Embracing digital networks: Entrepreneurs' social capital online. Journal of Business Venturing, 32(1), 18-34. https://doi. org/10.1016/j.jbusvent.2016.10.003

Stasik, A., \& Wilczynska, E. (2018). How do we study crowdfunding? An overview of methods and introduction to new research agenda. Journal of Management and Business Administration, 26(1), 49-78. https://doi.org/10.7206/jmba.ce.24507814.219

Stevenson, R.M., Kuratko, D.F., \& Eutsler, J. (2019). Unleashing main street entrepreneurship: Crowdfunding, venture capital, and the democratization of new venture investments. Small Business Economics, 52(2), 375-393. https://doi. org $/ 10.1007 /$ s11187-018-0097-2

Terre Blanche, M., \& Durrheim, K. (2002). Research in practice (1st edn.). Cape Town University of Cape Town Press.
Thürridl, C., \& Kamleitner, B. (2016). What goes around comes around? Rewards as strategic assets in crowdfunding. California Management Review, 58(2), 88-110. https://doi.org/10.1193/1.1585485

Vismara, S. (2018). Signaling to overcome inefficiencies in crowdfunding markets. In D. Cumming \& L. Hornuf (Eds.), The economics of crowdfunding: Startups, portals and investor behavior (1st edn , pp. 29-56). London: Palgrave Macmillan. https:// doi.org/10.1007/978-3-319-66119-3 3

Wang, N., Li, Q., Liang, H., Ye, T., \& Ge, S. (2018). Understanding the importance of interaction between creators and backers in crowdfunding success. Electronic Commerce Research and Applications, 27, 106-117. https://doi.org/10.1016/j. elerap.2017.12.004

Yu, S., Johnson, S., Lai, C., Cricelli, A., \& Fleming, L. (2017). Crowdfunding and regional entrepreneurial investment: An application of the CrowdBerkeley database. Research Policy, 46(10), 1723-1737. https://doi.org/10.1016/j. respol.2017.07.008

Zhang, B., Baeck, P., Ziegler, T., Bone, J., \& Garvey, K. (2016). Market trends in alternative finance size and growth of the different online alternative finance models. REPORT BY CAF (Cambridge Center for Alternative Finance- University of Cambridge Judge Business School), no. February, 1-56. Retrieved from https:// www.jbs.cam.ac.uk/fileadmin/user upload/research/centres/alternativefinance/downloads/2015-uk-alternative-finance-industry-report.pdf 